\title{
Role of routine abdominal ultrasonography in intensified tuberculosis case finding algorithms at HIV clinics in high TB burden settings
}

Sonam Spalgais ${ }^{1 \dagger}$, Upasna Agarwal ${ }^{1,2^{*+}} \mathbb{D}$, Rohit Sarin ${ }^{1}$, Devesh Chauhan ${ }^{1}$, Anita $_{\text {Yadav }}{ }^{1}$ and Anand Jaiswal ${ }^{1}$

\begin{abstract}
Background: High proportion of TB in people living with HIV (PLHIV) is undiagnosed. Due to this active TB case finding is recommended for HIV clinics in high TB burden countries. Presently sputum examination and chest radiography are frontline tests recommended for HIV infected TB presumptives. Abdominal TB which occurs frequently in PLHIV may be missed even by existing programmatic intensified case finding protocols. This study evaluated the routine use of ultrasonography (USG) for active case finding of abdominal TB in HIV clinics.
\end{abstract}

Methods: Retrospective analysis of eight years' data from an HIV Clinic in a TB hospital in India. Patients underwent chest x-ray, sputum examination, USG abdomen and routine blood tests at entry to HIV care. Case forms were scrutinized for diagnosis of TB, USG findings and CD4 cell counts. Abdominal TB was classified as probable or possible TB. Probable TB was based on presence of two major USG (abdomen) findings suggestive of active TB, or one major USG finding with at least two minor USG findings or at least two symptoms, or any USG finding with microbiologically confirmed active TB at another site. Possible TB was based on the presence of one major USG finding, or the presence of two minor USG findings with at least two symptoms. Bacteriological confirmation was not obtained.

Results: Eight hundred and eighty-nine people PLHIV underwent a baseline USG abdomen. One hundred and thirteen of 340 cases already diagnosed with TB and 87 of the 91 newly diagnosed with TB at time of HIV clinic registration had abdominal TB. Non-abdominal symptoms like weight loss, fever and cough were seen in 53\% and 22\% cases had no symptoms at all. Enlarged abdominal lymph nodes with central caseation, ascitis, splenic microabsesses, bowel thickening and hepatosplenomegaly were the USG findings in these cases.

Conclusions: Abdominal TB is a frequent TB site in PLHIV presenting with non-abdominal symptoms. It can be easily detected on basis of features seen on a simple abdominal ultrasound. Abdominal USG should be essential part of intensified TB case finding algorithms for HIV infected people living in high TB burden settings.

Keywords: HIV, TB, TB/HIV, USG, Abdominal TB

\footnotetext{
* Correspondence: u.agarwal@nitrd.nic.in

${ }^{\dagger}$ Equal contributors

${ }^{1}$ National Institute of TB and Respiratory Diseases, Sri Aurobindo Marg, New

Delhi 110030, India

${ }^{2}$ Kusuma School of Biological Sciences IIT Delhi, New Delhi, Hauz Khaz,

110016, India
} 


\section{Background}

Human immunodeficiency virus (HIV) associated tuberculosis (TB) continues to be a problem for both TB and HIV programs. As per the 2015 World Health Organization (WHO) report, globally only $50 \%$ of the estimated new HIV-TB cases were actually reported. The remaining either went undiagnosed or if diagnosed, the quality of care for people in this category is unknown [1]. Difficulties in correct and timely diagnosis of active TB in HIV infected populations is a barrier to effective HIV care, contributing to ongoing high morbidity and mortality seen with HIV associated TB $[1,2]$. For this reason, active TB case finding is recommended for HIV clinics in high TB burden countries. Presently sputum examination and chest radiographs are the recommended frontline tests for screening of HIV infected TB presumptives. However, not only is active TB in people living with HIV (PLHIV) often extra pulmonary, its diagnosis is challenging due to the atypical presentations of $\mathrm{TB}$, the frequent involvement of sites which are difficult to access which makes obtaining a clinical specimen difficult (especially in low-resource settings) and the presence of multiple opportunistic infections with overlapping symptoms [3, 4].

Abdominal TB, though infrequent in HIV uninfected people, is a common site of active TB in people living with HIV, especially in high TB burden countries [5-7] and may either present as the only site of active TB or may be seen alongside other affected sites like pulmonary, pleural, peripheral and intra thoracic lymph nodes [8]. TB of the abdomen may have non-specific symptoms and clinical specimens for bacteriological confirmation may not be easily available $[4,8]$. This makes its diagnosis difficult and the disease may go undetected unless specifically looked for. The morbidity and mortality of HIV-TB in general and HIV-extrapulmonary TB in particular is significant $[2,4,8]$ and enhanced efforts at early diagnosis are essential.

The Antiretroviral Therapy (ART) Centre at National Institute of TB and Respiratory Diseases (NITRD) is an HIV clinic in a referral TB Hospital providing free diagnostic and treatment services under the national TB and HIV control programs of the Government of India. With the aim to screen for pre-existing lesions and/or establish a baseline for possible future abdominal conditions (e.g. immune reconstitution inflammatory syndrome), an ultrasonography (USG) of the abdomen is carried out as part of routine pre-ART screening tests for all HIV patients entering long term care at our centre. For several years we observed USG findings suggestive of active abdominal TB in a significant number of PLHIV. Based on this observation and the results of a small prospective pilot study done to assess the role of different tests in diagnosis of HIVextra pulmonary TB [5], we undertook this data analysis to evaluate the role of routine abdominal ultrasonography for active case finding of abdominal TB in HIV clinics.

\section{Methods}

This study was a retrospective analysis of prospectively collected data for 1064 adult and adolescent HIV infected patients, registered between April 2006 and March 2014 at the Antiretroviral Therapy centre (ART centre) at National Institute of Tuberculosis and Respiratory Diseases, a tertiary care TB institute in New Delhi, India. All patients were ART naive at entry to HIV care. At the time of registration, HIV infected patients underwent a symptom screening, physical examination, baseline chest $x$-ray, sputum examination, abdominal ultrasonography (USG) and routine blood tests. Patients already diagnosed with active TB and on anti-tubercular treatment (ATT) at time of registration also underwent the pre-ART screening work up. Data in standardized case forms was available for all the cases. The case forms were scrutinized for diagnosis of $\mathrm{TB}$, type of $\mathrm{TB}$ (pulmonary/extrapulmonary or both), site of TB if extrapulmonary TB, abdominal USG findings and CD4 cell counts. Data was extracted and entered in standard research forms. HIV cases were grouped into those already diagnosed with $\mathrm{TB}$ at time of ART registration and those newly diagnosed with TB at the ART Centre at the time of entry in HIV care. Abdominal USG reports were analysed in detail for the presence of findings suggestive of abdominal TB.

\section{Diagnosis of HIV}

HIV infection was diagnosed using three antigenically different rapid kits as per the national HIV testing policy [9].

\section{Diagnosis of TB}

Active TB in HIV positive patients already diagnosed with TB as well as those newly diagnosed at the ART Centre was as per the existing WHO and Revised National Tuberculosis Control Program (RNTCP) guidelines. The diagnosis was based on identification of typical clinical features, with isolation of acid fast bacilli (AFB) from a clinical specimen wherever possible and/or the presence of radiological (chest radiographs/USGs/CT scans) findings suggestive of TB. TB was classified as either pulmonary TB (smear-positive or smear-negative), or extrapulmonary TB or both [10].

\section{Diagnosis of abdominal TB}

Abdominal TB in an HIV infected person was diagnosed on basis of USG (abdomen) findings with/without symptoms suggestive of TB. The USG findings and symptoms taken to be suggestive of active abdominal TB are as follows: (A) Major USG findings - i) multiple, enlarged lymph nodes in the abdomen of $>1.5 \mathrm{~cm}$ with central necrosis seen as area of hypoechogenicity, with or without matting ii) ascites (B) Minor USG findings - i) thickened bowel loops ii) splenic microabscesses iii) hepatosplenomegaly (C) Symptoms taken to be suggestive of TB - current fever, weight loss, cough of any duration and abdominal complaints. Active 
abdominal TB was further classified as probable or possible. The criterion used for classifying probable and possible abdominal TB is shown in Table 1. Bacteriological confirmation of abdominal lesions was not obtained in this study; therefore no abdominal TB diagnoses were definite or microbiologically confirmed.

\section{Abdominal ultrasonography}

The abdominal USGs were performed on either a Samsung Medison (Model SONOACE X8) machine or a SEIMENS G50 machine, by one of two clinical radiologists (medical doctors) with more than five years experience as specialists. All USGs were reported in structured formats as a standard hospital practice.

\section{Data analysis}

The extracted data was compiled and analysed using Microsoft Office Excel software. Continuous data is presented as median and inter-quartile range (due to extreme values) and categorical data is presented as percentages. Proportions were compared using a Fischer exact test and quantitative data was compared using a t-test. All tests were two tailed and a $p$ value of $<.05$ was considered significant.

This study was approved by the Institutional Review Board of National Institute of Tuberculosis and Respiratory Diseases.

\section{Results}

One thousand sixty four adult patients infected with HIV were registered at the ART Centre of National Institute of Tuberculosis and Respiratory Diseases, New Delhi between April 2006 and March 2014 for ART initiation. Of these, a baseline abdominal USG report was available for 889 HIV patients as part of their pre-ART screening workup (Fig. 1 shows details of HIV infected cases included in the analysis). Three hundred and forty people living with HIV were already on ATT for active TB at the time of ART registration, of which 239 had pulmonary TB (PTB) alone or in combination with extrapulmonary TB (EPTB). The

Table 1 Diagnostic criterion for probable and possible abdominal TB

Probable TB (any one of the below)
a) Two major USG findings
b) One major USG finding with at least two minor USG findings
c) One major USG finding with at least two symptoms
suggestive of TB
d) Any USG finding suggestive of TB with presence of
microbiologically confirmed TB at another site
Possible TB (any one of the below)
a) One major USG finding
b) Two minor USG findings with at least two symptoms
suggestive of TB

remaining 101 already known cases of TB were of EPTB alone. All of the 340 cases had an USG abdomen at entry to HIV care and 113 (33.2\%) subsequently revealed abdominal TB on USG abdomen, 56 of which had probable and 57 had possible abdominal TB as per our study criterion. Of the 549 HIV patients without a prior diagnosis of TB, $91(16 \%)$ were newly diagnosed as active TB at the HIV clinic at the time of registration. These diagnoses were made as a combined result of the intensified TB case finding procedures (sputum examination and chest radiography of symptomatic cases) and due to the USG examination undertaken as a pre-ART screening test. Of these newly diagnosed TB patients, one had only PTB (sputum smear positive for AFB), one case had both PTB and EPTB (smear negative $\mathrm{PTB}$ with AFB positive cervical lymph node aspirate) and 89 had only EPTB. Of these 89 new TB cases with only EPTB, one case had pleural effusion and one had cervical lymphadenopathy (with cytology reports suggestive of TB). The remaining 87 cases were diagnosed as abdominal TB. Forty-one of these 87 abdominal TB patients were classified as probable and 43 as possible abdominal TB on basis of the study criterion. There were 3 patients among these 87 who did not meet the criteria of probable or possible abdominal TB but had been given ATT on the basis of unexplained fever/abdominal pain with thickened bowel loops. Their treatment may be considered as on an empirical basis. However, in all these 87 cases, the abdomen was the only site of active TB. The details of microbiologically confirmed and clinically diagnosed TB cases in both the above groups are given in Table 2.

On a whole, there were a total 458 HIV patients without TB and 431 HIV patients with active TB disease in the cohort (Patient screening characteristics are given in Table 3) and of the total 200 cases treated as abdominal TB, 197 could be classified as either probable or possible abdominal TB. Details of their abdominal ultrasonography findings are given in Table 4 and the diagnostic criterion for probable and possible TB in cases people already diagnosed with active TB and those newly diagnosed with active TB are given in Table 5. The median CD4 cell count of cases with active abdominal TB was 111 cells/ $\mu$ l (IQR 68-200).

Along with weight loss, fever, cough, diarrhoea and abdominal pain, the other symptoms reported were abdominal pain, breathlessness and loss of appetite (Table 6). One hundred and six (53\%) patients with HIV-abdominal TB had only constitutional symptoms with no abdominal symptoms, while 54 (22\%) of the 200 HIV-abdominal TB patients did not have any symptom at presentation to the ART Clinic. We found diarrhoea as the most common abdominal complaint, seen in 94 (47\%) of HIV-abdominal TB patients, of which diarrhoea alone was present in 32 . Cough was present in 24 of the only abdominal TB patients with no evidence of PTB. 


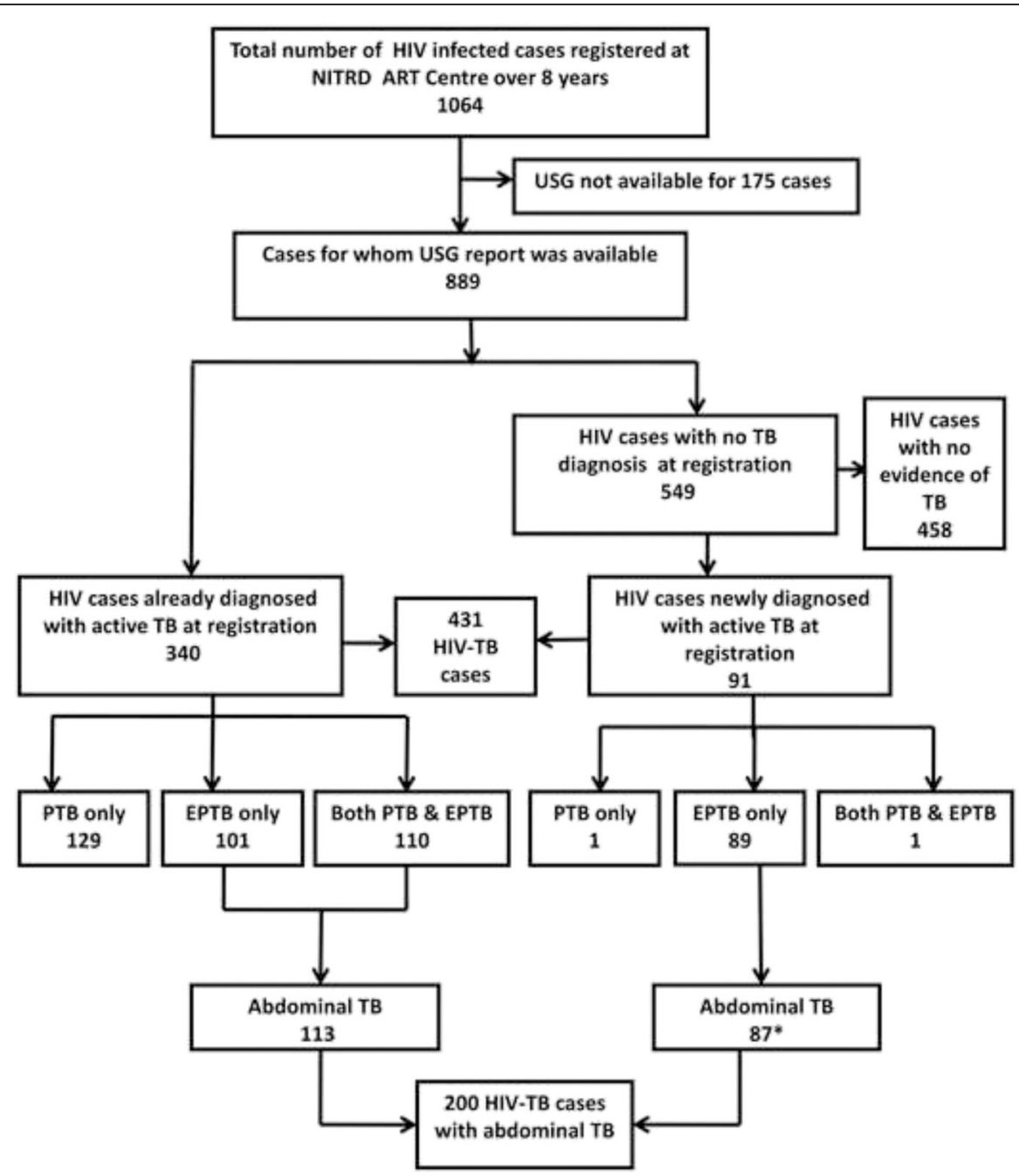

*Three cases treated as abdominal TB on basis of one minor USG finding with one symptom do not meet the criterion of possible abdominal TB.

Fig. 1 Details of HIV infected cases registered at NITRD ART Centre included in the analysis.

\section{Discussion}

Extra-pulmonary TB is a predominant form of TB in HIV infected people, of which the abdomen is a frequent site $[4,6-8,11-13]$. As abdominal TB presents with nonspecific symptoms [14-16] and has a low index of suspicion, the likelihood of it's under diagnosis becomes high.
In our study too, the symptoms in the majority of HIV abdominal TB patients (53\%) were constitutional or nonabdominal, that is fever, weight loss and cough. Though, these are important screening symptoms for active TB in HIV patients [17], they do not specifically indicate abdominal involvement and do not differ from symptoms seen

Table 2 Microbiologically confirmed and clinically diagnosed HIV-TB cases

\begin{tabular}{|c|c|c|c|c|c|c|}
\hline HIV cases screened & $\begin{array}{l}\text { No TB or } \\
\text { new TB }\end{array}$ & $\begin{array}{l}\text { HIV-TB } \\
\text { cases }\end{array}$ & $\begin{array}{l}\text { Microbiologically } \\
\text { confirmed TB cases }\end{array}$ & $\begin{array}{l}\text { PTB +/- EPTB } \\
\text { (microbiologically } \\
\text { confirmed TB) }\end{array}$ & $\begin{array}{l}\text { EPTB only } \\
\text { (microbiologically } \\
\text { confirmed TB) }\end{array}$ & $\begin{array}{l}\text { Abdominal TB } \\
\text { (Probable/ Possible) }\end{array}$ \\
\hline $\begin{array}{l}\text { Cases already on ATT } \\
\text { at entry }(n=340)\end{array}$ & 0 & 340 (known TB cases) & 102 & $239(72)$ & $101(30)$ & $113(56 / 57)$ \\
\hline $\begin{array}{l}\text { Cases not known to } \\
\text { have TB at entry } \\
(n=549)\end{array}$ & 458 & 91 (new TB diagnosis) & 2 & $2(2)$ & $89(0)$ & $\begin{array}{l}87(41 / 43)+3 \text { cases treated } \\
\text { as abdominal TB empirically }\end{array}$ \\
\hline TOTAL & 458 & 431 & 104 & 241 (74) & $190(30)$ & $200(97 / 100)$ \\
\hline
\end{tabular}

PTB= Pulmonary $\mathrm{TB} ; E P T B=$ Extra pulmonary $\mathrm{TB} ; A T T=$ anti-tubercular therapy,$+/-=$ with or without 
Table 3 Patient screening characteristics

\begin{tabular}{|c|c|c|c|}
\hline $\begin{array}{l}\text { Patient Characteristics } \\
(N=889)\end{array}$ & $\begin{array}{l}\text { Only HIV cases } \\
(n=458)\end{array}$ & $\begin{array}{l}\text { HIV-TB cases } \\
(n=431)\end{array}$ & $p$ value \\
\hline Male Gender, n (\%) & $296(64.6 \%)$ & $339(78.6 \%)$ & 0.0001 \\
\hline Media Age, years $(\mathrm{IQR})^{\mathrm{a}}$ & $34(30-40)$ & $34(30-39)$ & 0.35 \\
\hline $\begin{array}{l}\text { Median CD4 cell count, } \\
\text { cells/ul (IQR) }\end{array}$ & 214 (119-334) & $126(67-226)$ & $<0.0001$ \\
\hline
\end{tabular}

Interquartile range

among patients with HIV - non-abdominal TB or even HIV alone. Moreover, 32 (16\%) of the abdominal TB patients had diarrhoea as the only abdominal complaint, which overlaps with the general symptoms of HIV and $22 \%$ reported no symptoms at all. This implies that it would be easy to miss the diagnosis of abdominal TB in clinical practice, unless specifically looked for, especially if

Table 4 Abdominal ultrasound examination findings in HIV cases with abdominal TB

\begin{tabular}{|c|c|}
\hline Abdominal ultrasound examination findings & No. of patients (\%) \\
\hline $\begin{array}{l}\text { Enlarged lymph nodes }{ }^{a} \text {, thickened } \\
\text { bowel loops \& hepatosplenomegaly }\end{array}$ & $6(3)$ \\
\hline $\begin{array}{l}\text { Enlarged lymph nodes }{ }^{a} \text {, thickened } \\
\text { bowel loops \& ascites }\end{array}$ & $2(1)$ \\
\hline $\begin{array}{l}\text { Enlarged lymph nodes }{ }^{a} \text {, splenic } \\
\text { micro-abscesses \& hepatosplenomegaly }\end{array}$ & $5(2.5)$ \\
\hline $\begin{array}{l}\text { Enlarged lymph nodes }{ }^{\mathrm{a}} \text {, splenic } \\
\text { micro-abscesses \& ascites }\end{array}$ & $2(1)$ \\
\hline $\begin{array}{l}\text { Enlarged lymph nodes }{ }^{\mathrm{a}} \text {, } \\
\text { hepatosplenomegaly \& ascites }\end{array}$ & $1(0.5)$ \\
\hline $\begin{array}{l}\text { Enlarged lymph nodes }{ }^{a} \\
\& \text { thickened bowel loops }\end{array}$ & $9(4.5)$ \\
\hline $\begin{array}{l}\text { Enlarged lymph nodes }{ }^{a} \\
\& \text { splenic micro-abscesses }\end{array}$ & $16(8)$ \\
\hline $\begin{array}{l}\text { Enlarged lymph nodes } \\
\& \text { hepatosplenomegaly }\end{array}$ & $35(17.5)$ \\
\hline Enlarged lymph nodes ${ }^{a} \&$ ascitis & $4(2)$ \\
\hline $\begin{array}{l}\text { Thickened bowel loops } \\
\& \text { hepatosplenomegaly }\end{array}$ & $12(6)$ \\
\hline Thickened bowel loops \& ascites & $1(0.5)$ \\
\hline $\begin{array}{l}\text { Splenic micro-abscesses } \\
\& \text { hepatosplenomegaly }\end{array}$ & $2(1)$ \\
\hline Splenic micro-abscesses \& ascites & $1(0.5)$ \\
\hline Enlarged lymph nodes only & $88(44)$ \\
\hline Ascites only & $4(2)$ \\
\hline Thickened bowel loops onlyc & $9(4.5)$ \\
\hline Splenic micro-abscesses only ${ }^{c}$ & $3(1.5)$ \\
\hline
\end{tabular}

${ }^{a}$ Multiple abdominal lymph nodes, more than $1.5 \mathrm{~cm}$ in size with areas of central necrosis seen as hypoechogenecity on USG, with or without evidence of matting

${ }^{\mathrm{b}}$ Two minor USG findings were supported by presence of at least two symptoms suggestive of TB or microiologically confirmed TB at another site 'One minor USG findings were supported by presence of microbiologically confirmed TB at another site general TB symptoms are associated with a negative chest radiograph and sputum examination result.

In our study, $79 \%(n=340)$ of the HIV-TB patients had a prior diagnosis of TB at entry to HIV care. An USG in these cases showed features suggestive of abdominal TB in a high proportion (33.2\%) of cases. This is mainly due to the fact that this group was a preselected population of TB cases and abdomen was an additional site of TB and a manifestation of dissemination of TB in the context of HIV $[8,17]$. While in HIV patients with no prior diagnosis of TB ( $n=549$ ), a much lower proportion of abdominal TB was diagnosed $(15.8 \%, n=87)$. Nevertheless, this too is a significant number of TB cases diagnosed and in this group of patients the role of a routine USG is especially relevant for timely diagnosis and treatment. In cases already diagnosed with TB at entry to HIV care, abdominal USG may have limited usefulness as these patients will in any case receive TB treatment, treating abdominal TB as well.

Though a microbiological diagnosis is difficult to obtain for abdominal TB, a simple ultrasonic examination of the abdomen, which is both easy to perform and widely available, is mostly sufficient to diagnose abdominal TB. Unlike the symptoms, there are some typical (and multiple) radiological features suggestive of tubercular disease activity [18, 19]. Enlargement of multiple abdominal lymph nodes (> $1.5 \mathrm{~cm}$ ), with or without matting, with zones of hypoechogenecity representing caseation, hypoechoic lesions in the spleen indicative of splenic microabscesses, bowel loop thickening and ascites are the main features considered suggestive of active TB in the abdomen by several authors of HIV-TB studies, from India and globally [4, 20-24]. In our patients, enlarged abdominal lymph node with central necrosis, a finding which is easy to detect on USG abdomen, requiring minimal training and a simple USG machine, was the common USG finding. CT scan confirmation is necessary in few cases [5]. Interestingly, only 4 of our HIV-abdominal TB patients, had ascites alone, and ascitis with other USG findings was seen in 9 more cases. This lower number of ascitis cases may be due to the fact that ascites is easier to diagnose clinically and these cases might have been diagnosed earlier (in gastroenterology or general surgical clinics) without the need for active case finding. Moreover, ascites in some cases may have rapidly cleared with treatment, therefore not see on USGs done after a certain duration of anti-tubercular therapy [25]. There is some evidence to suggest that TB ascites is less frequent in HIV infected as compared to HIV uninfected case [2], though a study done by Sinkala et al. at a referral hospital in Zambia, reports ascites on USG in a high proportion of abdominal TB-HIV cases (16/22) [24]. The reason for higher number of ascites cases in this study maybe due to the study population of hospitalized symptomatic HIV patients, in whom ascites was one of their criteria for patient inclusion to further undergo a laparoscopy 
Table 5 Diagnostic criterion for probable and possible abdominal TB among cases already diagnosed and those newly diagnosed as TB at entry to HIV care

\begin{tabular}{|c|c|c|}
\hline \multirow{2}{*}{$\begin{array}{l}\text { Abdominal ultrasound findings } \\
\text { suggestive of } T B^{d}\end{array}$} & \multicolumn{2}{|l|}{ Number of abdominal TB cases $(N=200)^{a}$} \\
\hline & $\begin{array}{l}\text { Already diagnosed with TB at another site } \\
\text { at entry to HIV Clinic }\left(N=113^{\mathrm{b}} / 340\right)\end{array}$ & $\begin{array}{l}\text { Newly diagnosed at entry to } \\
\text { HIV clinic }\left(N=87^{a, c} / 91\right)\end{array}$ \\
\hline \multicolumn{3}{|l|}{ Probable abdominal TB cases $(n=97)$} \\
\hline 1. Two Major findings & 2 & 4 \\
\hline $\begin{array}{l}\text { 2. One major with at least two } \\
\text { minor findings }\end{array}$ & 1 & 6 \\
\hline $\begin{array}{l}\text { 3. One major finding with at } \\
\text { least two symptoms }\end{array}$ & 1 & 31 \\
\hline \multicolumn{3}{|l|}{$\begin{array}{l}\text { 4. USG findings in cases with } \\
\text { microbiolgically confirmed } \\
\text { TB at another site: }\end{array}$} \\
\hline $\begin{array}{l}\text { - Two major findings }(n=3) \\
\text { - One major \& two minor findings }(n=4) \\
\text { - One major finding alone or with one } \\
\text { minor finding/one symptom }(n=33) \\
\text { - Two minor findings with more than two } \\
\text { symptoms }(n=3) \\
\text { - One minor finding }(n=9)\end{array}$ & 52 & $\begin{array}{l}\text { None of the abdominal TB cases in this } \\
\text { group had TB at another site }\end{array}$ \\
\hline \multicolumn{3}{|l|}{ Possible abdominal TB cases $(n=100)$} \\
\hline 1. One major finding & 51 & 38 \\
\hline $\begin{array}{l}\text { 2. Two minor findings with at least } \\
\text { two symptoms }\end{array}$ & 6 & 5 \\
\hline
\end{tabular}

/ colonoscopy to obtain a clinical sample for microbiological examination. Their findings may be expected to differ from this study which is done in an out-patient clinic and included asymptomatic cases.

The differential diagnosis for HIV infected people with abdominal USG findings as seen in this study (enlarged lymph nodes, hepatosplenomegaly, bowel loop thickening), especially considering the low CD4 cell count of our cases, would mainly be disseminated non-tuberculous mycobacteria- Mycobacterium avium complex (MAC), fungal diseases like histoplasmosis, gram negative enteric infections like salmonellosis, Kaposi's sarcoma and

Table 6 Presenting symptoms in cases with HIV-abdominal TB $(N=200)$

\begin{tabular}{ll}
\hline Presenting symptom $^{\text {a }}$ & No. of patients (\%) \\
\hline Weight loss & $135(72.5)$ \\
Fever & $128(64)$ \\
Cough & $96(48)$ \\
Diarrhoea & $94(42)$ \\
Abdominal Pain & $60(30)$ \\
Breathlessness & $52(26)$ \\
Loss of appetite & $45(22.5)$ \\
\hline
\end{tabular}

${ }^{\mathrm{a}}$ More than two symptoms were seen in $64.5 \%$ cases lymphomas [26]. Diagnosis of abdominal lesions is usually made simpler in these conditions by coincident involvement of other sites like lung, skin or peripheral lymph nodes. Additionally, mycobacterial blood cultures for MAC, fungal blood cultures, antigen detection tests for Histoplasma andstool/blood cultures for Salmonella and other bacterial infections would be useful in arriving at a diagnosis [27, 28]. However, in the case of Kaposi's sarcoma and lymphomas, where no peripheral lesions are present, a diagnostic laparoscopy would be required for tissue biopsy and histopathological examination [29].

In this paper we highlight the problem of diagnosing abdominal TB in people living with HIV. Despite the frequency of the problem and availability of a simple and easy method of diagnosis, abdominal TB is under diagnosed in people living with HIV as there is no specific presenting symptom or sign $[2,3,14-16]$. As per current intensified case finding (ICF) protocols, HIV infected persons first go through symptom screening and those found to be symptomatic undergo a sputum examination and chest radiograph as frontline tests. An abdominal USG would usually not be ordered by the physician for an HIV-TB presumptive in the absence of abdominal symptoms. At our Centre, in addition to following the ICF protocol, we undertake USG (abdomen) as part of pre-ART screening investigations for all 
cases (with or without known TB) and were able to identify 200 cases of abdominal TB on the basis of the USG findings, in 87of which the abdomen was the only site of active TB. Given the non specificity of symptoms of abdominal TB, in some of these HIV cases the diagnosis of active TB might have been missed or delayed in the absence of a USG abdomen, despite routine ICF.

Our study is limited by the absence of microbiological (smear/culture) confirmation of abdominal TB, which precludes the availability of drug sensitivity testing (DST). Mycobacterial drug sensitivity testing, an important laboratory investigation in $\mathrm{TB}$, is especially critical for deciding further treatment options in patients not responding to TB treatment. The absence of DST is a serious limitation of USG based diagnosis of abdominal TB. Moreover, this study was conducted in a referral TB hospital, due to which a majority of the HIV patients who presented were already diagnosed with active TB at the time of referral to HIV care. Therefore results might vary if only general HIV infected populations are screened. For HIV patients already diagnosed with active TB at the time of registration to the HIV clinic, detailed information on TB diagnosis and treatment (e.g. prior duration of TB treatment etc) were not available, correspondingly we could not analyze the relation of USG findings and symptoms to these parameters. Also, we could not analyse the effect of varying ranges of $\mathrm{CD} 4$ counts on the presentations of abdominal $\mathrm{TB}$ as the $\mathrm{CD} 4$ counts of our patients were quite low on a whole. Nonetheless, it is a precise retrospective review of data from a national TB Institute which cares for $\mathrm{TB}$ and HIV patients referred from all over north India.

\section{Conclusions}

Abdominal TB is a major site of active TB in HIV infected cases accessing HIV care in a free HIV Clinic in North India, and at times it may be the only TB site. A majority of HIV patients with abdominal TB presented either with non-specific or no symptoms, due to which TB may go unsuspected. An abdominal ultrasonography is a simple, easily available and specific modality for diagnosis of abdominal TB. An abdominal ultrasound needs to be part of intensified TB case finding algorithms, alongside sputum examination and chest radiographs, at HIV clinics in high TB burden countries to allow improved active TB detection and subsequent timely treatment.

\section{Abbreviations}

AFB: Acid fast bacilli; ART Centre: Anti Retroviral Therapy Centre;

ART: Antiretroviral therapy; ATT: Anti tubercular therapy; DST: Drug sensitivity testing; EPTB: Extra pulmonary tuberculosis; HIV: Human immunodeficiency virus; ICF: Intensified case finding; IQR: Interquartile range;

MAC: Mycobacterium avium intercellulare; NITRD: National Institute of TB \& Respiratory Diseases, New Delhi; PLHIV: People living with HIV;

PTB: Pulmonary tuberculosis; RNTCP: Revised National TB Control Program;

TB: Tuberculosis; USG: Ultrasonography; WHO: World Health Organization

\section{Acknowledgements}

The authors acknowledge the support of Dr. Aditya Mittal (Kusuma School of Biological Sciences, IIT Delhi) for useful discussions on analysis and interpretation of the data.

\section{Funding}

This work had no funding.

\section{Availability of data and materials \\ The datasets analysed during the current study are available from the corresponding author.}

\section{Authors' contributions \\ SS was responsible for acquisition of data and analysis and interpretation of data. UA was involved in conception and design of the study, acquisition and interpretation of data and drafting the manuscript. DC and AY were involved in revising the manuscript for scientific content. RS and AJ were involved in reviewing the manuscript critically for intellectual content. All authors read and approved the final manuscript.}

\section{Competing interests}

The authors declare that they have no competing interests.

\section{Consent for publication}

Not applicable.

\section{Ethics approval and consent to participate}

Ethics approval was taken for this data analysis from the Institutional Ethics Committee of National Institute of TB and Respiratory Diseases, New Delhi. Consent for using clinical data was taken from all patients who were in follow up of the clinic. Consent of patients who had died or were lost to follow up was waived off by the ethics committee as data was non-patient identifiable.

\section{Publisher's Note}

Springer Nature remains neutral with regard to jurisdictional claims in published maps and institutional affiliations.

Received: 26 September 2016 Accepted: 30 April 2017

Published online: 18 May 2017

\section{References}

1. World Health Organization. Global Tuberculosis Report 2015 [Internet]. Geneva: WHO; 2015 p. 82. Available from: http://www.who.int/tb/ publications/global_report/gtbr15_main_text.pdf

2. Fee M J, Oo M M, Gabayan A E, D. Radin R and Barnes P F. Abdominal tuberculosis in patients infected with the human immunodeficiency virus. Clin Infect Dis1995;20(4):938-944.

3. O'Keefe EA, Wood R, Van Zyl A, Cariem AK. Human immunodeficiency virusrelated abdominal pain in South Africa. Aetiology, diagnosis, and survival. Scand J Gastroenterol. 1998;33:212-7.

4. Heller T, Goblirsch S, Wallrauch C, Lessells R, and Brunetti E. Abdominal tuberculosis: sonographic diagnosis and treatment response in HIV-positive adults in rural South Africa. International Journal of Infectious Diseases.2010;1049.

5. Spalgais S, Jaiswal A, Puri MM, Sarin R, Agarwal U. Clinical profile and diagnosis of extrapulmonary TB in HIV infected patients: routine abdominal ultrasonography increases detection of abdominal tuberculosis. Indian J Tuberc. 2013:60:147-53.

6. Borkar MS,Joshi AS, KashidAA,Gawale CG, Kakade RD and Chimote HN. Clinical profile of $128 \mathrm{HIV}$ positive cases with abdominal tuberculosis. Int J Sci Rep 2016 Jan; 2(1):18-24.

7. Hiyasu Z, Babashani M. Prevalence and predictors of tuberculosis coinfection among HIV-seropositive patients attending the Aminu Kano teaching hospital, northern Nigeria. J Epidemiol. 2009;19:81-7.

8. Sharma SK, Mohan A, Kadhiravan T. HIV-TB co-infection: epidemiology, diagnosis and management. Indian J Med Res. 2005;121:550-67.

9. National AIDS Control Organization, Ministry of Health and Family Welfare Govt. of India. Anti retroviral therapy guidelines for HIV infected adult and adolescents including post exposure prophylaxis. New Delhi: Government of India; 2007 p. 7-8. 
10. Central TB Division, Directorate General of Health Services, Ministry of Health and Family Welfare, Govt. of India. Managing the Revised National Tuberculosis Control Program in your area. New Delhi: Govt. of India; 2005 p. 1-2.

11. Fanning A. Tuberculosis:Extrapulmonary disease. CMAJ. 1999:160:1597-603.

12. Agarwal $U$, Kumar A, Behera D. Profile of HIV associated tuberculosis at tertiary institute in setting of free anti retroviral therapy. JAPI. 2009;57:685-90.

13. Goblirsch S, Bahlas S, Ahmed M, Brunetti E, Wallrauch C, Helle T. Ultrasound findings in cases of extrapulmonary TB in patients with HIV infection in Jeddah, Saudi Arabia. Asian Pac J Trop Dis. 2014;4(1):14-7.

14. Jaryal A, Raina R, Sarkar M, Sharma A. Manifestation of tuberculosis in HIV/AIDS patients and its relationship with CD4 count. Lung India. 2011;28:263-6.

15. Kwara A, Roahen-Harrison S, Prystowsky E. et al. Manifestation and outcome of extrapulmonary tuberculosis: Impact of human immunodeficiency virus co-infection. Int.JTuerc Lung Dis. 2005;(5):485-93.

16. Trivedi A, Trivedi A, Panchal M, Jethva M, Yadav M. Abdominal ultrasonography findings in HIV infected patients. Sch J App Med Sci. 2015;3(1G):504-7.

17. Mohammed A, Enrlich R, Wood R, Cilliers F, Maartens G. Screening for tuberculosis in adults with advanced HIV infection prior to preventive therapy. Int J Tuberc Lung. 2004;8(6):792-5.

18. Lingenfelser T, Zak J, Marks IN, et al. Abdominal tuberculosis; still a potentially lethal disease. Am J Gastroenterol. 1993;88:744.

19. Lundstedt.C. Nyman R, Brismar J, Hugosson C and Kagevi I.Imaging Of Tuberculosis II. Abdominal manifestations in 112 patients. ActaRadiol 1996;37: 489-495.

20. Agarwal D, Narayan S, Chakravarty J, Sundar S. Ultrasonography for diagnosis of abdominal tuberculosis in HIV infected people. Indian J Med Res. July 2010:132:77-80

21. Obajimi M, Atalabi M, Ogbole G, Adeniji-Sofoluwe A, Agunloye A, Adekanmi A, et al. Abdominal ultrasonography in HIV/AIDS patients in southwestern Nigeria. BMC Med Imaging. 2008;8(1):5.

22. Kisembo H, Kawooya M, Kenyon C, Worodria W, Colebunders R. Abdominal sonographic findings in severely immunosuppressed human immunodeficiency virus-infected patients treated for tuberculosis. JTBRes. 2014:02(02):65-74.

23. Giordani MT. Et alExtrapulmonary mycobacterial infections in a cohort of HIV-positive patients: ultrasound experience from Vicenza, Italy. Infection. 2013 Apr;41(2):409-14.

24. Sinkala E, Gray S, Zulu I, et al. Clinical and ultrasonographic features of abdominal tuberculosis in HIV positive adults in Zambia. BMC Infect Dis. 2009;9:44.

25. Jain R, Sawhney S, Bhargava DK, Berry M. Diagnosis of abdominal tuberculosis: sonographic findings in patients with early disease. Am J Radiol. 1995:165:1391-5.

26. Gill PS, Arora DR, Arora B, et al. Lymphadenopathy an important guiding tool for detecting hidden HIV-positive cases: a 6-year study. J IntAssoc Physicians AIDS Care (Chic III). 2007 Dec;6(4):269-72.

27. Ioachimescu, O.C.: Tomford, J.W. Nontuberculous mycobacterial disorders. In Disease Management Project; Carey, W., Ed.; Cleveland Clinic-Centre for Continuing Education: Cleveland, OH, USA, 2015; Available online: http:// www.clevelandclinicmeded.com/medicalpubs/diseasemanagement/ infectious-disease/nontuberculous-mycobacterial-disorders/Default.htm (accessed on 15 January 2017).

28. Wheat L. Improvements in diagnosis of histoplasmosis. Expert OpinBiolTher. 2006Nov; 6(11):1207-21.

29. Bhandarkar DS, Shah RS, Katara AN, Shankar M, Chandiramani VA, Udwadia TE. Laparoscopic biopsy in patients with abdominal lymphadenopathy. J Minim Access Surg. 2007 Jan-Mar;3(1):14-8.

\section{Submit your next manuscript to BioMed Central and we will help you at every step:}

- We accept pre-submission inquiries

- Our selector tool helps you to find the most relevant journal

- We provide round the clock customer support

- Convenient online submission

- Thorough peer review

- Inclusion in PubMed and all major indexing services

- Maximum visibility for your research

Submit your manuscript at www.biomedcentral.com/submit
) Biomed Central 